\title{
Deep biopsy via endoscopic submucosal dissection for primary gastric amyloidosis
}

Amyloidosis is characterized by interference with multiple organs. It is usually systemic and uncommonly limited to the stomach [1,2]. Here we report a rare case of primary gastric amyloidosis.

A previously healthy 56-year-old man, whose family history was not significant for any digestive system tumors or blood disorders, presented to our institution with dyspepsia and weight loss lasting for one year. Esophagogastroduodenoscopy (EGD) showed multiple depressed superficial lesions at the greater curve of the gastric body ( Fig. $1 \mathbf{a}$ ). The lesions were whitish, and the boundaries were not clear. Gastric cancer and malignant lymphoma were suspected initially, but biopsy specimens revealed mild chronic atrophic gastritis. Notably, the lesions bled easily after biopsy, so we

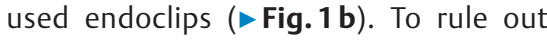
any missed diagnosis and misdiagnosis, we decided to perform a deep biopsy via endoscopic submucosal dissection (ESD) with informed consent. After evaluation of endoscopic ultrasonography (EUS) and magnification endoscopy with narrow band imaging, we removed one of the lesions en bloc in a specimen measuring $300 \times 270 \mathrm{~mm}$ ( $>$ Video 1). Unexpectedly, histopathological examination showed deposition of amyloid in the mucosal and submucosal layer ( Fig.2a) with the ability to bind Congo red ( Fig.2b), leading to green birefringence under polarized light ( $\triangleright$ Fig.2 c). Furthermore, light chain staining for kappa and lambda were positive. Additionally, we performed an enteroscopy and biopsies from the esophagus, duodenum, jejunum, ileum, and colon, all of which were negative for amyloid. Meanwhile, the patient received a systematic examination including blood biochemistry analysis, coagulation test, echocardiography, abdominal computed tomography (CT), serum-free light chain analysis, and protein electrophoresis, yet no abnormalities were found. Because other organs were unaffected, we diagnosed

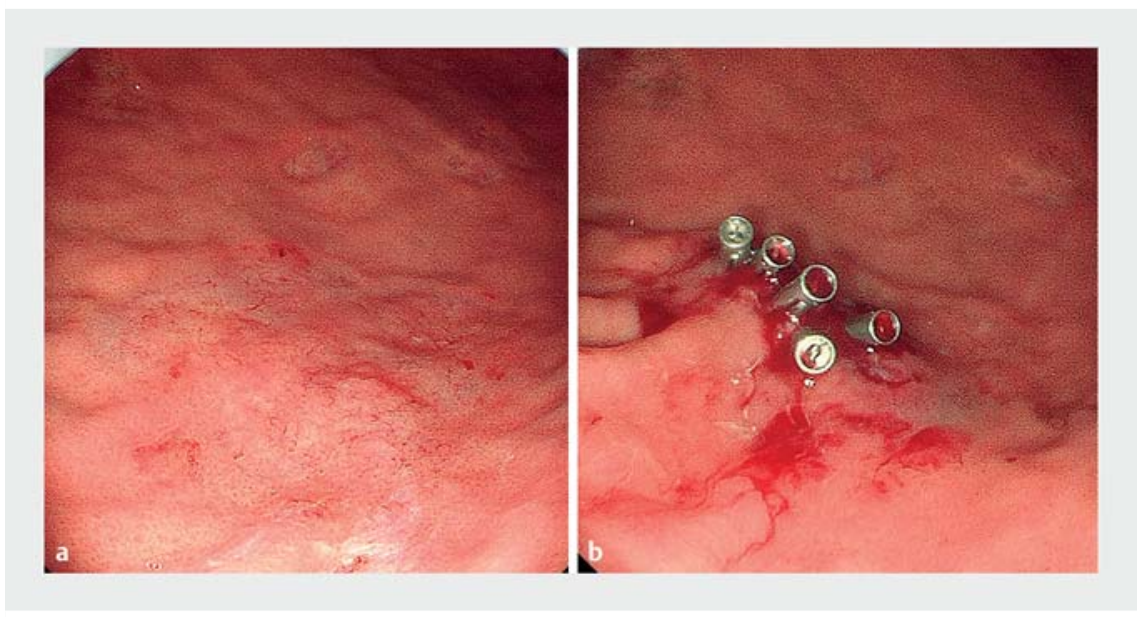

- Fig. 1 Endoscopic images show multiple depressed superficial lesions. a The lesions are whitish, and the boundaries are not clear. $\mathbf{b}$ The lesions bleed easily after biopsy, and endoclips are used.
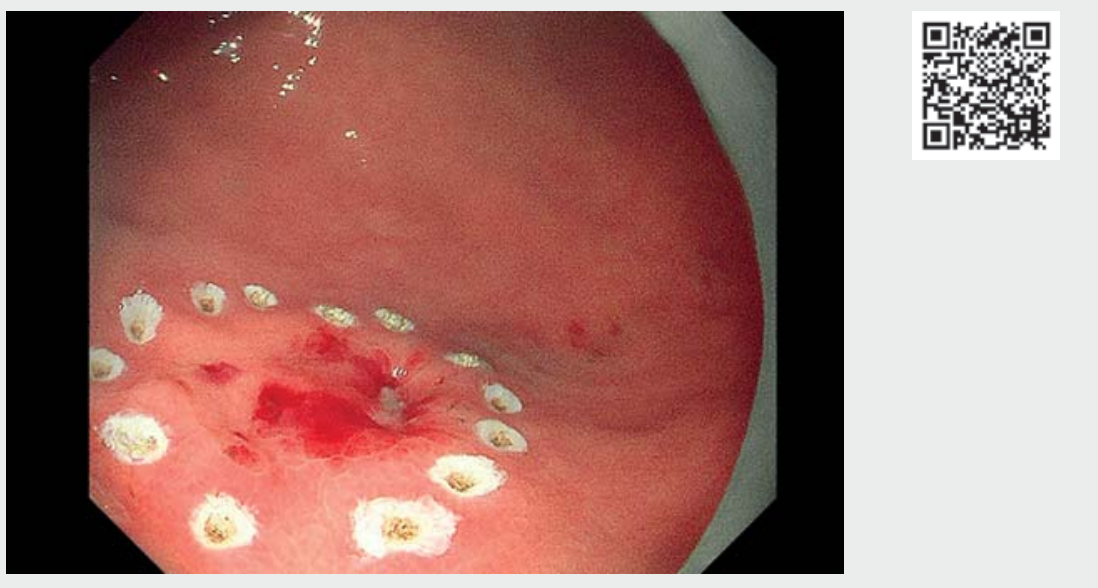

Video 1 Deep biopsy via endoscopic submucosal dissection for primary gastric amyloidosis.

gastric amyloidosis and endoscopic surveillance was arranged.

In conclusion, primary gastric amyloidosis remains challenging to diagnose because its appearance on endoscopy is not specific [3, 4]. However, when facing suspicious lesions, we endoscopists should be aware of amyloidosis and investigate further.
Endoscopy_UCTN_Code_CCL_1AB_2AZ_3AZ

Funding

Supported by the National Natural Science Foundation of China, http://dx.doi.org/10.13039/ 501100001809 82070575 


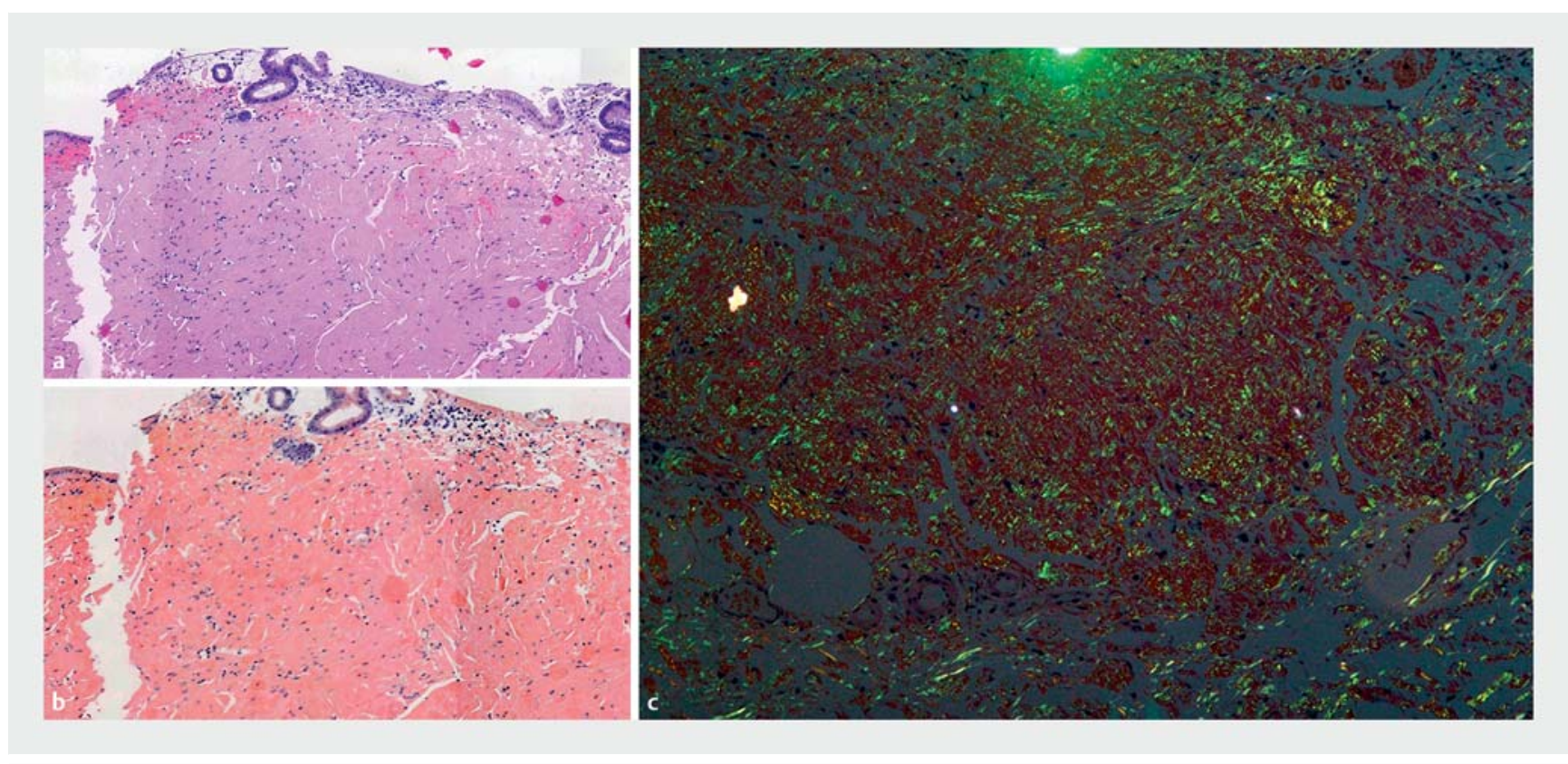

- Fig. 2 Histopathologic findings. a Hematoxylin and eosin staining shows deposition of amyloid in the mucosal and submucosal layer. b Congo red staining reveals amyloid deposition with orange-colored deposits in the mucosal and submucosal layer. c Green birefringence under polarized light.

\section{References}

Competing interests

The authors declare that they have no conflict of interest.

\section{The authors}

Zheng Zhao', Yue Jiao', Bing Yue ${ }^{2}$, Wenjing Wang', Guiping Zhao', Shutian Zhang', Peng Li ${ }^{1}$

1 Department of Gastroenterology, Beijing Friendship Hospital, Capital Medical University, Beijing, China

2 Department of Pathology, Beijing Friendship Hospital, Capital Medical University, Beijing, China

\section{Corresponding author}

\section{Peng Li, MD, PhD}

Beijing Friendship Hospital, No. 95 Yong'an Road, Xicheng District, Beijing 100050,

China

lipeng@ccmu.edu.cn
[1] Dahiya DS, Kichloo A, Singh J et al. Gastrointestinal amyloidosis: a focused review. World J Gastrointest Endosc 2021; 13: 1-12

[2] Cowan AJ, Skinner M, Seldin DC et al. Amyloidosis of the gastrointestinal tract: a 13-year, single-center, referral experience. Haematologica 2013; 98: 141-146

[3] Ebert EC, Nagar M. Gastrointestinal manifestations of amyloidosis. Am J Gastroenterol 2008; 103: 776-787

[4] Sawada T, Adachi Y, Akino K et al. Endoscopic features of primary amyloidosis of the stomach. Endoscopy 2012; 44 (Suppl 2 UCTN): E275-E276

Bibliography

Endoscopy 2022; 54: E236-E237

DOI 10.1055/a-1493-2081

ISSN 0013-726X

published online 8.6.2021

(c) 2021. Thieme. All rights reserved.

Georg Thieme Verlag KG, Rüdigerstraße 14,

70469 Stuttgart, Germany

\section{ENDOSCOPY E-VIDEOS}

https://eref.thieme.de/e-videos

口回 Endoscopy E-Videos is an Fen access online section, 自和: reporting on interesting cases and new techniques in gastroenterological endoscopy. All papers include a high quality video and all contributions are freely accessible online. Processing charges apply (currently EUR 375), discounts and wavers acc. to HINARI are available.

This section has its own submission website at https://mc.manuscriptcentral.com/e-videos 